\title{
Subintimal wire pathway: part of the game of crossing chronic total coronary occlusions
}

\author{
Nicolaus Reifart ${ }^{1}, \mathrm{MD}$; Gerald S. Werner ${ }^{2 *}$, MD \\ 1. Medizinische Klinik 1 (Kardiologie), Main-Taunus-Kliniken, Bad Soden, Germany; 2. Medizinische Klinik (Cardiology \& \\ Intensive Care), Klinikum Darmstadt GmbH, Darmstadt, Germany
}

The history of percutaneous recanalisation of chronic total coronary occlusions (CTO) reaches back to the mid 1980s when, little by little, stiffer wires appeared on the market. Most of the reports of CTO results in those days included "well selected cases" and used a more liberal definition including recent occlusions, so that the reported success rates of $>60 \%$ are not realistic with respect to the types of lesions treated today ${ }^{1}$. The steep improvement of success rates by dedicated CTO operators, now reaching $90 \%$ in Japan and also in Europe and other parts of the world, was made possible by the introduction of new techniques in the past ten years, spearheaded by pioneers like O. Katoh, H. Tamai and T. Suzuki, combined with educational efforts by groups like the Japanese, and the European CTO club ${ }^{2-4}$.

The most important milestones on the road to success were the development of dedicated wires with different physical characteristics (a development that is still ongoing), the availability of microcatheters, and of course the introduction of drug-eluting stents which made it possible to preserve the initial interventional success over time. The ultimate advance in success rates was achieved by the introduction of the retrograde technique, using the tiny collateral connections between donor artery and occluded vessels ${ }^{5}$. The retrograde approach rapidly gained wide appreciation and is applied by some operators in up to $30-50 \%$ of their CTO procedures, although it may require more time, material, dye and radiation than the antegrade approach, as depicted by the results of the Euro CTO club registry ${ }^{6}$.

One of the inherent problems of passing a wire through a CTO is the deviation into the subintimal space, and then the redirection into the true lumen. This can be achieved by using additional wire(s) in parallel, by attempting a re-entry with either stiff or alternatively soft polymeric wires. The latter is an attempt to salvage otherwise failed procedures by an uncontrolled re-entry, called STAR (subintimal tracking and re-entry) with very poor long-term outcome due to the extensive dissections ${ }^{7,8}$. However, even controlled antegrade techniques and especially the retrograde approach using the CART (controlled antegrade and retrograde subintimal tracking) manoeuvre to connect the wire positions of the antegrade and retrograde wire involve conceptually a subintimal pathway of the wire(s) ${ }^{9}$. The J-PROCTOR registry is one of the first studies to evaluate systematically the incidence of the subintimal wire pathway by using intravascular ultrasound (IVUS) before stent placement for the contemporary CTO recanalisation technique ${ }^{10}$. IVUS is certainly the best available method to verify coronary wall structure and the location of the wire pathway in these often complex and long lesions 9 .

Article, see page 681

The ratio of antegrade to retrograde procedures in the report by Muramatsu et $\mathrm{al}^{10}$ is $1: 2$, which is due to a selection bias as only procedures that were monitored by IVUS, which is used more often in retrograde than in antegrade procedures, were evaluated. Overall, 163 lesions were evaluated, which is certainly a sufficient number to evaluate the procedural technical details, but on the other hand does not provide enough power to draw reliable conclusions on long-term follow-up effects of the procedural technique. The observed incidence of a subintimal pathway was $12 \%$ in antegrade procedures, and a surprisingly low $24 \%$ in retrograde procedures. Apart from the relatively shorter stented segment compared with true lumen tracking, there is no quantitative information on the extension of the subintimal pathway, which would most likely have an impact on the later outcome and healing process of the implanted stents. On the other hand, this report shows us that the retrograde subintimal tracking and reentry as applied by experienced and skilful operators will more often create an intraplaque connection or result in a true lumen wire crossing in about $75 \%$ of cases. Those of us who are continually watching the most experienced Japanese operators doing live cases can confirm that they meticulously try to avoid or limit the subintimal course by checking with IVUS the optimal spot for connection within the occlusion body. In this registry, the retrograde group with subintimal course resulted in a stent length of $2.4 \mathrm{x}$ occlusion length while in those with intraplaque course it was 2.6x occlusion length, an impressive confirmation of their efforts to avoid a subintimal neolumen.

Interest in limiting the subintimal pathway is based on the adverse experience of low long-term patency with the uncontrolled STAR technique, which was hampered by poor initial run-off due to residual dissections. However, there is also the intuitive perception

\footnotetext{
* Corresponding author: Medizinische Klinik I, Klinikum Darmstadt, Grafenstrasse 9, D-64283 Darmstadt, Germany. E-mail: gerald.werner@klinikum-darmstadt.de
} 
that placing drug-eluting stents within the plaque may be better than placing them in a long subintimal pathway with partial and possibly extended contact with the thin adventitial layer directly. In fact, there are some hints from the J-PROCTOR registry that the number of aneurysms was higher with the subintimal pathway than without, although the numbers were small. On the whole, the long-term outcome over almost one year was very good for intimal and subintimal tracking, and showed no significant differences in clinical endpoints. However, there was a significantly greater late loss with the subintimal pathway, a higher percent restenosis, and a nominally higher incidence of reocclusions. These differences, which may adversely affect clinical endpoints, might become evident only in larger study populations. The present study supports the meticulous approach displayed by skilful operators in limiting subintimal pathways even with the retrograde technique.

The results reflect the experience of a group of experienced operators, and may not be transferred to other approaches which apply different strategies. Therefore, it is also premature to extend the findings in the J-PROCTOR registry to the controllable subintimal re-entry during the antegrade approach facilitated by the Stingray catheter reentry system (Boston Scientific, Natick, MA, USA) ${ }^{11,12}$. Unlike the STAR technique, this new approach achieves a controlled re-entry though often it cannot avoid long subintimal dissection planes, but initial reports showed high restenosis and reocclusion rates.

At a time when the procedural success of PCI in CTOs has achieved a level close to the treatment success in complex nonocclusive lesions, we should now concentrate all our efforts on securing the long-term effectiveness of our treatment, and specifically avoid vessel reocclusion. The J-PROCTOR registry shows the way to do this by applying IVUS to analyse the impact of various procedural techniques, but we need larger study populations to be able to draw real clinical conclusions.

\section{Conflict of interest statement}

$\mathrm{G}$. Werner is on the speaker bureau for ASAHI Intecc, Boston Scientific, Terumo Europe and Volcano Europe. N. Reifart has no conflicts of interest to declare.

\section{References}

1. Bell MR, Berger PB, Bresnahan JF, Reeder GS, Bailey KR, Holmes DR Jr. Initial and long-term outcome of 354 patients after coronary balloon angioplasty of total coronary artery occlusions. Circulation. 1992;85:1003-11.

2. Stone GW, Colombo A, Teirstein PS, Moses JW, Leon MB, Reifart NJ, Mintz GS, Hoye A, Cox DA, Baim DS, Strauss BH, Selmon M, Moussa I, Suzuki T, Tamai H, Katoh O, Mitsudo K, Grube E, Cannon LA, Kandzari DE, Reisman M, Schwartz RS, Bailey S, Dangas G, Mehran R, Abizaid A, Serruys PW. Percutaneous recanalization of chronically occluded coronary arteries: procedural techniques, devices, and results. Catheter Cardiovasc Interv. 2005;66:217-36.

3. Di Mario C, Werner GS, Sianos G, Galassi AR, Buttner J, Dudek D, Chevalier B, Lefevre T, Schofer J, Koolen J, Sievert H,
Reimers B, Fajadet J, Colombo A, Gershlick A, Serruys PW, Reifart N. European perspective in the recanalisation of Chronic Total Occlusions (CTO): consensus document from the EuroCTO Club. EuroIntervention. 2007;3:30-43.

4. Sianos G, Werner GS, Galassi AR, Papafaklis MI, Escaned J, Hildick-Smith D, Christiansen EH, Gershlick A, Carlino M, Karlas A, Konstantinidis NV, Tomasello SD, Di Mario C, Reifart N; EuroCTO Club. Recanalisation of chronic total coronary occlusions: 2012 consensus document from the EuroCTO club. EuroIntervention. 2012;8:139-45.

5. Surmely JF, Tsuchikane E, Katoh O, Nishida Y, Nakayama M, Nakamura S, Oida A, Hattori E, Suzuki T. New concept for CTO recanalization using controlled antegrade and retrograde subintimal tracking: the CART technique. J Invasive Cardiol. 2006;18:334-8.

6. Galassi AR, Tomasello SD, Reifart N, Werner GS, Sianos G, Bonnier H, Sievert H, Ehladad S, Bufe A, Shofer J, Gershlick A, Hildick-Smith D, Escaned J, Erglis A, Sheiban I, Thuesen L, Serra A, Christiansen E, Buettner A, Costanzo L, Barrano G, Di Mario C. In-hospital outcomes of percutaneous coronary intervention in patients with chronic total occlusion: insights from the ERCTO (European Registry of Chronic Total Occlusion) registry. EuroIntervention. 2011;7:472-9.

7. Colombo A, Mikhail GW, Michev I, Iakovou I, Airoldi F, Chieffo A, Rogacka R, Carlino M, Montorfano M, Sangiorgi GM, Corvaja N, Stankovic G. Treating chronic total occlusions using subintimal tracking and reentry: the STAR technique. Catheter Cardiovasc Interv. 2005;64:407-11; discussion 412.

8. Valenti R, Vergara R, Migliorini A, Parodi G, Carrabba N, Cerisano G, Dovellini EV, Antoniucci D. Predictors of reocclusion after successful drug-eluting stent-supported percutaneous coronary intervention of chronic total occlusion. $\mathrm{J}$ Am Coll Cardiol. 2013;61:545-50.

9. Sumitsuji S, Inoue $\mathrm{K}$, Ochiai $\mathrm{M}$, Tsuchikane $\mathrm{E}$, Ikeno $\mathrm{F}$. Fundamental wire technique and current standard strategy of percutaneous intervention for chronic total occlusion with histopathological insights. JACC Cardiovasc Interv. 2011;4:941-51.

10. Muramatsu T, Tsuchikane E, Oikawa Y, Otsuji S, Fujita T, Ochiai M, Kawasaki T, Abe M, Sakurada M Kishi K. Incidence and impact on midterm outcome of controlled subintimal tracking in patients with successful recanalisation of chronic total occlusions; J-PROCTOR registry. EuroIntervention. 2014:10:681-8.

11. Werner GS, Schofer J, Sievert H, Kugler C, Reifart NJ. Multicentre experience with the BridgePoint devices to facilitate recanalisation of chronic total coronary occlusions through controlled subintimal re-entry. EuroIntervention. 2011;7:192-200.

12. Brilakis ES, Michael TT, Papayannis AC, Patel V, Fuh E, Alomar M, Moin D, Brayton K, Mogabgab O, Shorrock D, Navara R, Tran DL, Roesle M, Rangan BV, Haagen D, Makke L, Abdullah S, Luna M, Addo T, Banerjee S. AngiographiC Evaluation of the Everolimus-Eluting Stent in Chronic Total Occlusions (ACECTO): angiographic outcomes (NCT 01012869). Paper presented at TCT 2012, Miami, FL, USA. http://www.tctmd.com/show. aspx?id=114101 